\title{
Hubungan Komunikasi Interpersonal, Disiplin Kerja Dan Lingkungan Kerja Terhadap Kinerja Pegawai Kantor Pusat LPP TVRI
}

\author{
Dira Karlina \\ Dosen Fakultas Ekonomi Universitas Pamulang \\ Email:dirakarlina5@gmail.com
}

\begin{abstract}
ABSTRAK
Komunikasi interpersonal, disiplin kerja, dan lingkungan kerja pegawai yang di duga mempunyai hubungan yang berdampak pada peningkatan kinerja pegawainya.Penelitian ini bertujuan untuk mengetahui hubungan antara komunikasi interpersonal, disiplin kerja, dan lingkungan kerja pegawai terhadap kinerja pegawai Kantor Pusat LPP TVRI.

Penelitian ini merupakan penelitian kuantitatif dengan analisis deskripsi dan korelasi pearson.Populasi penelitian seluruh pegawai Kantor Pusat LPP TVRI sejumlah 361 orang, teknik pengambilan sampel dengan propibillity sampling ditemukan sampel 78 orang dengan menggunakan rumus slovin.Hasil uji korelasi pearson pada variabel komunikasi interpersonal diperoleh angka 0,262 dan nilai $p$ value $=0,032$ lebih kecil dari $\alpha=0,05$ maka Ho di tolak, hal ini menunjukan bahwa terdapat hubungan antara komunikasi interpersonal dengan kinerja pegawai yang signifikan walau tingkat hubunganya "rendah".

Sedangkan variabel disiplin kerja dan lingkungan kerja tidak terdapat hubungan terhadap kinerja pegawai, masing-masing ditunjukan nilai sebesar 0,163 dan nilai $\mathrm{p}$ value $=0,186$ lebih besar dari $\alpha=0,05$, dan sebesar 0,036 dan nilai $\mathrm{p}$ value $=0,771$ lebih besar dari $\alpha=0,05$ maka Ho di terima, hal ini menunjukan bahwa tidak terdapat hubungan, Namun terdapat hubungan yang positif dan signifikan antara variabel-variabel independen.
\end{abstract}

Kata kunci : komunikasi interpersonal, disiplin kerja, lingkungan kerja, kinerja pegawai. 


\section{PENDAHULUAN}

Sumber daya manusia merupakan sumber daya yang potensial dan merupakan kekuatan organisasi, karena sumber daya manusia yang menjalankan dan menggerakkan organisasi tersebut.Untuk menggerakkan organisasi diperlukan sumber daya manusia yang jumlahnya cukup banyak disertai perbedaan-perbedaan antara pribadi yang satu dengan pribadi lainnya.Permasalahan pokok terletak pada peranan sumber daya manusia pada suatu organisasi, untuk mendapatkan kehidupan yang layak dan mempunyai hak mendapatkan pekerjaan yang sesuai dengan nilainilai kemanusiaan. Jika hal ini diabaikan oleh instansi atau organisasi, maka kegagalan yang dicapai.

Kinerja yang meningkat dalam suatu organisasi dapat dicapai jika pimpinan menyadari sepenuhnya bahwa sumber daya manusia dalam organisasi merupakantool of management dan harus benar-benar dalam keadaan produktif.

Salah satu usaha yang dapat dilakukan adalah mengembalikan timbulnya semangat dan gairah pada pegawai tersebut. Sebagaimana dikemukakan (Iskandar, 2006), untuk mendorong timbulnya semangat dan gairah pada diri Pegawai dapat dilakukan dengan jalan :

1) Menciptakan suasana kerja yang harmonis, kondusif

2) Memberikan kompensasi berupa insentif

3) Memperhatikan kebutuhan rohani bagi pegawai.

4) Menempatkan pegawai pada posisi yang tepat.
5) Memberikan kesempatan kepada pegawai untuk maju.

Komunikasi interpersonal yang baik dan efektif sangat diperlukan oleh manusia agar dia dapat menjalani semua aktivitasnya dengan lancar, terutama ketika seseorang melakukan aktivitas dalam situasi yang formal, misalnya dalam lingkungan kerja.Aktivitas kerja seseorang lebih penting jika berhadapan langsung dengan orang lain, yang sebagian besar kegiatannya merupakan kegiatan komunikasi interpersonal, jika kondisi ini diabaikan, akan terjadi kesenjangan dan pada akhirnya menyebabkan menurunnya kinerja.

Dalam rangka pengembangan sumber daya manusia yang berkualitas, komunikasi interpersonal atau komunikasi antar pribadi harus diarahkan kepada kebutuhan organisasi. Menurut Muhammad (2005:158-159), komunikasi interpersonal didefinisikan sebagai proses pertukaran informasi diantara seseorang dengan paling kurang seorang lainnya atau biasanya di antara dua orang yang dapat langsung diketahui balikannya. Faktor yang perlu menjadi perhatian jika kita berbicara mengenai hubungan komunikasi interpersonal dengan kinerja adalah membangun hubungan kepercayaan antara sumber dan sasaran komunikasi.

Fenomena yang terjadi pada Kantor Pusat LPP TVRI adalah kemampuan dan kecepatan pegawai dalam menyelesaikan tugas dari atasannya yang sering tidak tepat waktu, sikap karyawan yang tidak sepenuh hati dalam menjalankan tugasnya dan yang lebih ironis adalah sikap 
karyawan yang pasif yang menunggu perintah dari atasannya saja, tidak memiliki kreatifitas dan inovasi dalam menjalankan tugasnya untuk dapat membantu perkembangan perusahaan sebagai pecapaian tujuan organisasi.

Disiplin merupakan bentuk pengendalian diri pegawai dan pelaksanaan yang teratur dan menunjukan tingkat kesungguhan tim kerja di dalam perusahaan. Disiplin diri adalah suatu ciri atau tanda dari kematangan pribadi yang begitu luas.Kepribadian manusia terdiri dari sejumlah aspek yang masing-masing mengandung banyak unsur.

Menurut Sedarmayanti (2007:339), disiplin merupakan salah satu unsur pokok dalam upaya mencapai kualitas dan keberhasilan manajemen, disamping unsur pemahaman serta komitmen, ketiadaan salah satu unsur tersebut mempunyai dampak kualitas manajemen yang kurang baik,oleh karena itu disiplin harus mampu ditanamkan pada seluruh sumber daya manusia dalam manajemen, melalui cara :

1) Mengenal diri sendiri.

2) Mendisiplinkan diri.

3) Memimpin dengan keteladanan.

4) Menanamkan semangat kemandirian.

5) Menghindari sikapdan perilaku negatif.

6) Anggaplah disiplin itu ibadah.

Disiplinpegawai, tidak lepas dari masalah mengenai keseluruhan nilai budaya kerja yang diharapkan dapat dikembangkan oleh setiap pegawai, sehingga antara nilai-nilai yang diyakini dan kerja akan menumbuhkan tanggung jawab terhadap peningkatan kinerja.

Lingkungan kerja yang merupakan salah satu faktor penting dalam menciptakan kinerja pegawai dan mempunyai pengaruh langsung bagi pegawai dalam menyelesaikan pekerjaannya, sehingga pada akhirnya akan meningkatkan kinerja organisasi. Suatu kondisi lingkungan kerja dikatakan baik apabila karyawan dapat melaksanakan kegiatan secara optimal, sehat, aman, dan nyaman.Hal yang menjadi pengamatan penulis terkait lingkungan kerja pada Kantor Pusat LPP TVRI, terdapat banyak ruangan yang pemanfaatannya belum maksimal, banyak ruangan kosong yang hanya dipergunakan untuk gudang, tampak perawatan pada peralatan-peralatan kantor dan gedung yang kurang maksimal, beberapa peralatan-peralatan teknik yang rusak dalam waktu yang lama untuk dilakukannya perbaikan.

\section{Kajian Pustaka,}

Berasal dari pengertian performance.Ada pula yang memberikan pengertian performance sebagai sesuatu hasil yang telah dikerjakan atau prestasi kerja. Namun sebenarnya kinerja mempunyai makna yang lebih luas, bukan hanya hasil kerja, tetapi termasuk bagaimana proses pekerjaan berlangsung.Menurut Sedarmayanti (2007:260), performance is defined as the record of outcomes produced on a specific job function or activity during a specific timeperiode (kinerja didefinisikan sebagai catatan mengenai outcome yang dihasilkan dari suatu aktivitas tertentu, selama kurun waktu tertentu).Menurut 
Soelaiman (2007:280), kinerja sebagai sesuatu yang dikerjakan dan dihasilkan dalam bentuk produk maupun jasa, dalam suatu periode tertentu dan ukuran tertentu oleh seseorang atau sekelompok orang melalui kecakapan, kemampuan, pengetahuan dan pengalamannya.

Hasil kerja seorang pegawai merupakan sebuah proses manajemen secara keseluruhan, dimana hasil kerja tersebut harus dapat ditujukkan buktinya secara kongkrit dan dapat diukur. Menurut Wibowo (2007:8) memandang manajemen kinerja sebagai proses komunikasi yang dilakukan secara terus menerus dalam kemitraan antara pegawai dan atasan langsungnya. Manajemen kinerja hanya sebagai salah satu gaya manajemen, namun dari sisi substansinya sebagai suatu proses komunikasi.Wibowo

(2007:9).Manejemen kinerja mendukung tujuan menyeluruh organisasi dengan mengaitkan pekerjaan dari setiap pegawai dan pimpinan pada misi keseluruhan dari unit kerjanya. Seberapa baik kita mengelola kinerja staf akan secara langsung mempengaruhikinerja masing-masing staf secara individu, unit kerjanya, serta kinerja seluruh organisasi.Wibowo (2007:11). Dengan demikian manajemen kinerja memerlukan kerjasama, saling pengertian, komunikasi secara terbuka antara atasan dan staf.

\section{Prinsip Dasar Manajemen Kinerja.}

Manajemen kinerja bekerja atas prinsip dasar yang dijadikan acuan bersama agar dapat mencapai hasil yang diharapkan.Prinsip dasar manajemen kinerja menjadi pondasi yang kuat bagi kinerja organisasi untuk mencapai tujuan.Menurut Wibowo (2007:11) ada beberapa prinsip dasar manajemen kinerja diantaranya sebagai berikut :

1) Kejujuran dalam mengekpresikan pendapat, menyampaikan fakta, memberikan pertimbangan dan perasaan.

2) Memberikan pelayanan yang baik kepada stakeholder, sebagai kinerja yang diberikan pegawai dalam mencapai tujuan organisasi .

3) Memahami dan menerima tanggung jawab atas apa yang dikerjakan dan yang tidak dikerjakan untuk mencapai tujuan.

4) Menerapkan prinsip bermain dalam manajemen kinerja.

5) Memahami dan empati terhadap orang lain. Menunjukan rasa kasian pada diri orang lain dan diri sendiri.

6) Manajemen kinerja dimulai dengan melakukan perumusan dan organisasi.

7) Mengandalkan konsesus dan kerjasama antara atasan dan bawahan daripada menekannkan pada control dan melakukan paksaan.

8) Manajemen kinerja merupakan suatu proses yang sifatnya berlangsung terus menerus, berkelanjutan, bersifat evolusioner, dimana kinerja secara bertahap selalu diperbaiki sehingga menjadi semakin baik.

9) Manajemen kinerja memerlukan gaya manajemen yang terbuka, jujur serta mendorong terjadinya 
komunikasi dua arah antara atasan dan staf.

\section{Komunikasi Interpersonal.}

Manusia sebagai mahkluk sosial yang selalu ingin berhubungan dan berinteraksi dengan manusia lainnya, serta ingin mengetahui apa yang terjadi dengan lingkungannya, rasa ingin tahu inilah yang memaksa manusia untuk berkomunikasi.Komunikasi adalah kebutuhan yang sangatmendasar/fundamental bagi seseorang dalam hidup bermasyarakat.MenurutSoelaiman (2007:225), komunikasi dan informasi dinyatakan sebagai berikut :" Comunication maybe defined as the transfer of information from one person to another through signs, signal or simbols from a mutually understood launguange system". Dalam organisasi komunikasi membantu individu menyesuaiakan diri dengan berbagai perubahan dan karenanya harus dilakukan komunikasi kinerja secara teratur. Pimpinan yang baik akan memberikan sebanyak mungkin informasi kepada semua pegawai, guna mengetahui tentang informasi sasaran kinerja, arah tujuan dan tugas-tugasnya. Komunikasi yang dilakukan secara terus menerus memberikan kewenangan pada para pegawai untuk bekerja dan mengambil keputusan secara mandiri.Menurut Rakhmat (2000:80), ada beberapa faktor yang mempengaruhi komunikasi interpersonal, yaitu :

1) Hubungan Interpersonal adalah relasional antara pihak-pihak yang terkait dalam hubungan individu satu dengan individu lain dalam kelompok sosial.Adapun faktor yang mempengaruhi hubungan interpersonal adalah :

a) Kepercayaan (trust)

b) Sikap Supportivitas (supportiveness)

c) Penerimaan adalah kemampuan seseorang berhubungan dengan orang lain tanpa menilai dan tanpa berusaha mengendalikannya.

d) Empati

e) Kejujuran

2) Konsep Diriadalah pandangan atau perasaan kita tentang diri kita sendiri.

3) Atraksi Interpersonaladalah arah dari hubungan komunikasi interpersonal.

4) Persepsi Interpersonal adalah Persepsi seseorang berkaitan erat dengan kebutuhan yang dimiliki.

\section{Hambatan Dalam Komunikasi Manajemen Kinerja.}

Hakikatnya komunikasi sebagai suatu system, hambatan komunikasi bisa terjadi pada semua elemen atau unsur-unsur yang mendukungnya, termasuk faktor lingkungan dimana komunikasi itu terjadi, untuk mengetahui hambatan dan cara mengatasinya,kita hendaknya mengetahui arah komunikasi.Arah komunikasi dalam keorganisasian yaitu komunikasi vertical, komunikasi horizontal,komunikasi diagonal.Hubungan komunikasi yang efektif adalah komunikasi dan perlakuan yang menghasilkan pemahaman bersama antara pimpinan dan staf sehingga menimbulkan rasa senang dan puas 
antar kedua belah pihak.Kondisi ini menimbulkan tanggapan berupa rasa memiliki terhadap organisasi dan seluruh kegiatannya serta diikuti rasa tanggung jawab terhadap pekerjaan kemudian kemauan ikut berpartisipasi.

\section{Disiplin Kerja.}

Menurut Veitzhal (2004:444) adalah suatu alat yang digunakan pimpinan untuk berkomunikasi dengan karyawan agar mereka bersedia mengubah suatu perilaku sertaberupaya meningkatkan kesadaran, kesediaan seseorang untuk mentaati semua peraturan perusahaan dan norma-norma sosial yang berlaku.

Disiplin yang baik mencerminkan besarnya rasa tanggung jawab seseorang terhadap tugas-tugas yang diberikan kepadanya.Hal ini mendorong gairah kerja, semangat kerja, dan terwujudnya tujuan perusahaan, karyawan serta masyarakat pada umumnya.

Disiplin adalah bentuk pengendalian diri pegawai dan pelaksanaan yang teratur dan menunjukan tingkat kesungguhan tim kerja dalam suatu organisasi, yang pada akhirnya membuat suatu penekanan terhadap disiplin yang dapat membuat pegawai mampu bergairah untuk bekerja begitu pula sebaliknya.Proses tindakan disiplin berhubungan luas dengan pelanggaran peraturanperaturan,berikut Gambar Proses Tindakan Disiplin :

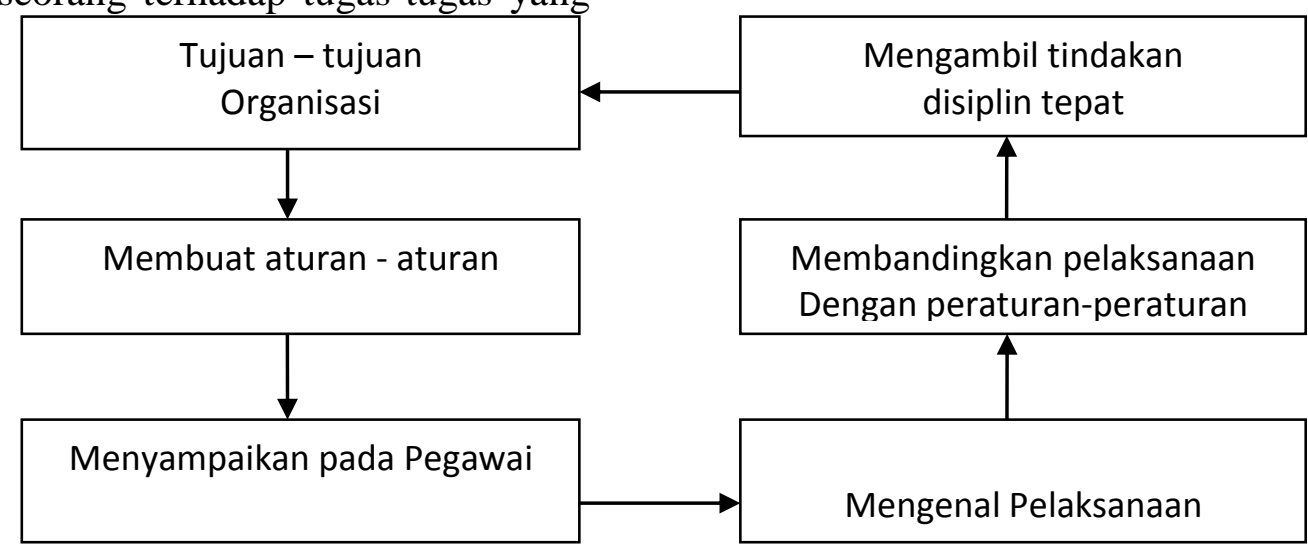

Gambar. 2.1.

Sumber: Iwan Iskandar (2006)

Proses Tindakan Disiplin

Gambar di atas menunjukan bahwa pada saat perilaku seorang pegawai melanggaraturan, maka tindakan korektif mungkin diperlukan.Tujuan tindakan ini adalah mengubah tipe perilaku yang dapat memiliki dampak negatif terhadap pencapaianpencapaian tujuanorganisasi. Tindakan disiplin diambil agar para pegawai menyadari bahwa perilaku tertentu tidak dapat diterima dan tidak boleh terulang lagi. Dan jika tindakan disiplin yang tepat tidak diambil, maka pegawai akan memandang perilaku tersebut dapat diterima atau akan mengulanginya.

Peraturan sangat diperlukan untuk memberikan bimbingan dan penyuluhan bagi pegawai dalam menciptakan tata tertib yang baik 
diperusahaan. Dengan tata tertib yang baik, semangat kerja, moral kerja, efisiensi, dan efektivitas kerja pegawai akan meningkat.

Menurut Malayu S.P Hasibuan (2006:214) mengemukakan bahwa faktor-faktor yang mempengaruhi disiplin kerja antara lain :

1) Tujuan dan kemampuan

2) Teladan pimpinan

3) Balas jasa

4) Keadilan

5) Pengawasan melekat

6) Sanksi hukuman

7) Ketegasan pimpinan

8) Hubungan kemanusiaan yang harmonis

\section{Lingkungan Kerja.}

Adalah tempat dimana karyawan melakukan aktivitas setiap harinya. Lingkungan kerja yang kondusif memberikan rasa amam dan memungkinkan karyawan untuk dapat bekerja dengan optimal. Lingkungan kerja dapat mempengaruhi emosi karyawan, karyawan akan betah ditempat kerjanya jika karyawan tersebut menyenangi lingkungan kerjanya dan melakukan aktivitasnya sehingga waktu kerja dapat dipergunakan secara efektif, lingkungan kerja mencakup hubungan kerja baik itu sesama karyawan maupun antara bawahan dan atasan, serta lingkungan fisik tempat karyawan bekerja.

Menurut Sedarmayanti (2009:31) lingkungan kerja fisik adalah semua keadaan berbentuk fisik yang terdapat di sekitar tempat kerja yang dapat mempengaruhi karyawan baik secara langsung maupun secara tidak langsung.Sedangkan lingkungan kerja nonfisik adalah semua keadaan yang terjadi berkaitan dengan hubungan kerja, baik hubungan dengan atasan maupun dengan rekan kerja, ataupun hubungan dengan bawahan.Penelitian ini di fokuskan pada bagaimana pegawai mendapatkan rasa aman, nyaman, tentram, dan terciptanya hubungan yang harmonis, serta rasa puas dalam menyelesaikan pekerjaannya didalam ruang kerjanya.

Faktor-Faktor Lingkungan Kerja. Secara garis besar lingkungan kerja dipengaruhi beberapa faktor diantaranya sebagai berikut:

1) Fasilitas Kerja, lingkungan kerja yang kurang mendukung pelaksanaan pekerjaan akan menjadikan kinerja buruk, seperti kurangnya alat kerja, ruang kerja yang pengap, fentilasi kurang dan prosedur yang tidak jelas.

2) Gaji dan tunjangan, yang tidak sesuai dengan harapan pekerja akan membuat pekerja melirik pada lingkungan kerja yang lebih menjaminnya.Hubungan kerja, kelompok kerja dengan kekompakan dan loyalitas yang tinggi akan meningkatkan produktivitas kerja.

\section{Penelitian Terdahulu}

1. Beny Usman (2013).Pengaruh Komunikasi Interpersonal Terhadap Kinerja Pegawai Pada Fakultas Ekonomi Universitas PGRI Palembang Hasil Penelitian mengatakan bahwa Komunikasi Interpersonal berpengaruh kuat Terhadap Kinerja Pegawai pada Fakultas Ekonomi Universitas PGRI Palembang. Hal ini di tunjukan 
dengan hasil perhitungan persamaan regresi linier sederhana diperoleh yaitu $\mathrm{Y}^{\prime}=$ $8,867+0,762 \mathrm{X}$ di mana nilai a $=8,867$ dan nilai $\mathrm{b}=0,762$. Ini bearti pengaruh antara komunikasi interpersonal terhadap kinerja pegawai Fakultas Ekonomi Universitas PGRI Palembang dapat diketahui dengan melihat kenaikan nilai $\mathrm{X}$ yang diikuti pula dengan kenaikan nilai $\mathrm{Y}$ yang bearti jika komunikasi ditingkatkan maka kinerja pegawai pada fakultas Ekonomi Universitas PGRI Palembang akan ikut meningkat. Selanjutnya perhitungan dengan menggunakan koefisien korelasi ( $\mathrm{R}$ ) diperoleh nilai sebesar 0,764 maka karena hasilnya positif bearti ada hubungan yang kuat dan positif antara komunikasi interpersonal dan kinerja pegawai. Sedangkan dengan melihat koefisien korelasi dari hasil perhitungan dapat digeneralisasikan atau tidak , maka dengan membandingkan rrtabelbila taraf kesalahan $5 \%$ dengan $\mathrm{n}=31$ maka diperoleh ŗtabel0,355, karena nilai rhitunglebih besar dari nilai ŗtabel $(0,674>0,355)$ sehingga Ho di terima. Jadi kesimpulannya ada hubungan positif dan signifikan sebesar 0,764 antara komunikasi interpersonal terhadap kinerja pegawai pada fakultas Ekonomi Universitas PGRI Palembang.

2. Nuria Erisna. (2012). Dalam jurnal yang berjudul Hubungan Disiplin dan Motivasi Kerja Dengan Kinerja Pegawai Pada
Dinas Pendidikan Kabupaten Way Kanan, mengatakan bahwa terdapat hubungan yang kuat antara disiplin kerja terhadap kinerja pegawai.

3. Penelitian terdahulu yang ditulis Nina Munira Naharuddin., Mohammad Sadegi. (2013).Factors Workplace Environment that Affect Employees Performance : A Case Study of Miyazu Malaysia. Sebuah penelitian yang menghasilkan bahwa lingkungan kerja berpengaruh positif terhadap kinerja pegawai.

\section{Hipotesis}

Hipotesis dalam penelitian ini sebagai berikut:

H1 : Diduga terdapat hubungan yang positif dan signifikan antara Variabel Komunikasi Interpersonal terhadap Kinerja Pegawai.

$\mathrm{H} 2$ : Diduga terdapat hubungan yang positif dan signifikan antara Variabel Disiplin Kerja terhadap Kinerja Pegawai.

H3 : Diduga terdapat hubungan yang positif dan signifikan antara Variabel Lingkungan Kerja terhadap Kinerja Pegawai.

H4 : Diduga terdapat hubungan yang positif dan signifikan antara Dimensi Komunikasi Interpersonal dengan terhadap Disiplin Kerja.

H5 : Diduga terdapat hubungan yang positif dan signifikan antara Dimensi Komunikasi Interpersonal terhadap Lingkungan Kerja.

H6 : Diduga terdapat hubungan yang positif dan signifikan 
antara Disiplin Kerja terhadap Lingkungan Kerja.
Kerangka pemikiran secara ringkas diilustrasikan kedalam gambar berikut :

\section{Kerangka Pemikiran}

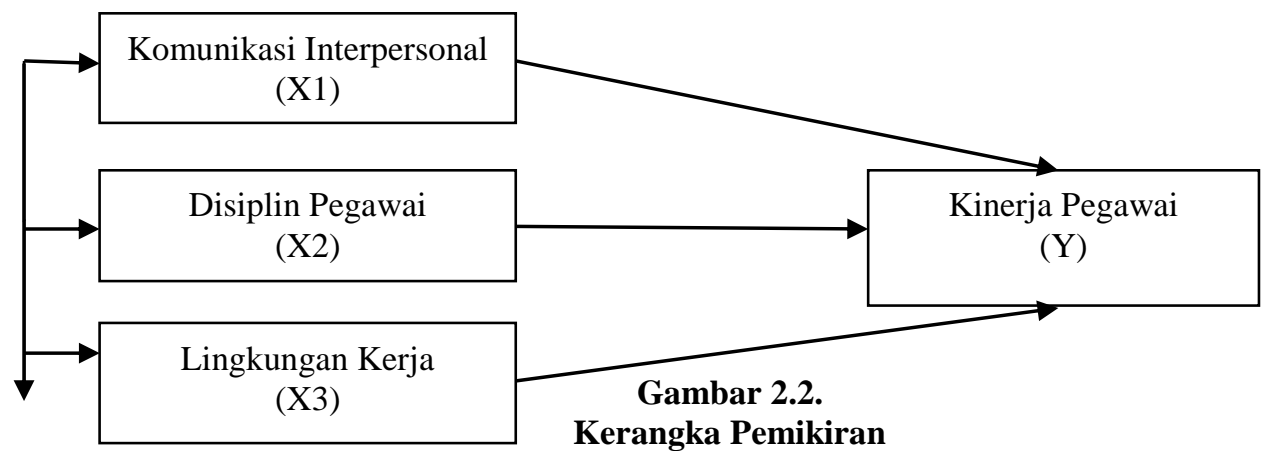

Sumber: Data diolah Peneliti (2015)

\section{Metode Penelitian}

1. Populasi dan Teknik Sampling Populasi dalam penelitian ini adalah pegawai Direktorat Program dan Berita Kantor Pusat LPP TVRI, dengan teknik pengambilan sampling menggunakan metode stratified random sampling, dengan sampel sebanyak 78 orang.

2. Operasional Variabel

Tabel 3.1.

Operasional Variabel

\begin{tabular}{lllc}
\hline \multicolumn{1}{c}{ Variabel } & \multicolumn{1}{c}{ Dimensi } & \multicolumn{1}{c}{ Indikator } & Skala Ukur Data \\
\hline Komunikasi & Komunikasi & a. Hubungan & Likert \\
Interpersonal & Interpersonal & KerjaVertikal & \\
(X1) & (formal) & b. Hubungan & \\
& & KerjaHorizontal & \\
& & c. Hubungan Kerja & \\
& & Diagonal & \\
& Komunikasi & a. Interaksi socialantar & \\
& Interpersonal & pegawai dalam jam & \\
& (In formal) & kerja & \\
& & b. Interaksi sosial antar & \\
& & pegawai diluar jam & \\
& & kerja \\
\hline Disiplin Kerja & 1. Kesejahteraan & 1. Insentif & \\
(X2), & 2. Kepemimpinan & 2. Fasilitas \\
& 3. Pengawasan & 3. Lingkungan Kerja & \\
& & 4. Perhatian & \\
& & 5. Keadilan & \\
& & 6. Pengawasan & \\
\hline
\end{tabular}

\begin{tabular}{ll}
\hline Lingkungan & 1. Fasilitas \\
Kerja & Kerja \\
(X3) &
\end{tabular}

2. Gaji dan

a. Alat Kerja Likert

(X3)

b. Ruang Kerja

c. Fentilasi

d. Prosedur yang tidak jelas

a. Gaji yang tidak sesuai

3. Hubungan

a. Kekompakan

b. Loyalitas 


\begin{tabular}{|c|c|c|c|}
\hline \multicolumn{4}{|c|}{$\begin{array}{l}\text { Jurnal Ilmiah, Manajemen Sumber Daya Manusia } \\
\text { JENIUS }\end{array}$} \\
\hline $\begin{array}{l}\text { Kinerja } \\
\text { karyawan }(\mathrm{Y})\end{array}$ & 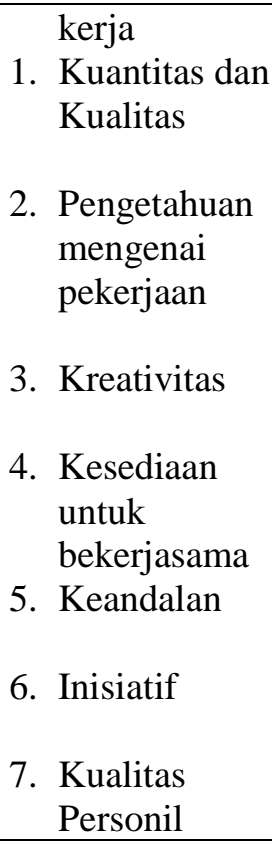 & $\begin{array}{l}\text { c. Produktivitas } \\
\text { 1. Memiliki kuantitas } \\
\text { dan kualitas kerja } \\
\text { 2. Memiliki pengetahuan } \\
\text { tentang pekrjaan yang } \\
\text { ditugaskan } \\
\text { 3. Memiliki kreativitas } \\
\text { 4. Bersedia bekerjasama } \\
\text { 5. Handal dalam } \\
\text { menyelesaikan } \\
\text { pekerjaan } \\
\text { 6. Memiliki Inisiatif } \\
\text { 7. Memiliki kemampuan } \\
\text { dalam memimpin }\end{array}$ & Likert \\
\hline
\end{tabular}

Sumber: Data Diolah Peneliti.(2015)

\section{Jenis dan Sumber Data}

Jenis data yang digunakan adalah data primer yang bersifat kuantitatif dan data sekunder yang diambil dari dokumen perusahaan.Sumber data dan informasi dalam penelitian ini menggunakan data primer dan data sekunder.

\section{a. Teknik Pengumpulan Data}

Teknik pengumpulan data melalui kuesioner dan dokumentasi.

\section{b. Validasi Penelitian}

Pengujian validitas dengan menggunakan program SPSS dengan metode Pearson Correlation, yaitu mengkorelasikan tiap item dengan skor total item kuisioner.Dasar pengambilan keputusan uji validitas (Alhusin, 2003:165).sebagai berikut:Jika $\mathrm{r}_{\text {hitung }}>\mathrm{r}_{\text {tabel }}$, maka item pertanyaan dinyatakan valid.Jika $\mathrm{r}_{\text {hitung }}<\mathrm{r}_{\text {tabel }}$ atau $\mathrm{r}$ hitung negatif, maka item pertanyaan dinyatakan tidak valid.Jika Nilai $r$ table dapat dilihat pada table statistik $r$ dengan $\mathrm{N}=$ atau $\mathrm{df}=\mathrm{n}-2=$ dan dengan signifikansi 0,05 maka didapat nilai $\mathrm{r}$ tabel $=$ Hasil pengujian .

\section{c. Reliabilitas Intrumen}

Menurut Ghazali (2005:189). Dasar pengambilan keputusan untuk pengujian reliabilitas adalah sebagai berikut : Jika nilai Cronbach Alpha> 0,60, maka kuesioner yang diuji dinyatakan reliabel.Jika nilai Cronbach Alpha< 0,60, maka kuesioner yang diuji dinyatakan tidak reliabel.Item-item yang masuk dalam uji reliabilitas adalah semua item yang valid, sedangkan yang tidak valid dikeluarkan.

\section{d. Uji Normalitas Data}

Uji normalitas dilakukan dengan uji Kolmogorov-smirnov.

\section{e. Metode Analisis Data}

Metode analisis yang digunakan adalah metode analisis korelasi pearson.

\section{f. Analisis Korelasi}


MenurutSugiyono(2010:250), untuk menginterpretasikan hasil koefisien korelasi adalahsebagai berikut:

1. $0,00-0,199=$ sangat rendah

2. $0,20-0,399=$ rendah

3. $0,40-0,599=$ sedang

4. $0,60-0,799=$ kuat

5. $0,80-1,000=$ sangat kuat.

Nilai $r$ sekitar 0 sampai 1 atau -1 , semakin mendekati 1 atau -1 berarti hubungan yang terjadi semakin kuat.Sebaliknya jika nilai semakin mendekati 0 maka hubungan yang terjadi semakin lemah.

\section{Hasil dan Pembahasan Karakteristik Responden.}

Identitas Responden yang dapat dilihat dalam tabel-tabel beriku,t hanya berjumlah 40 responden saja, dikarenakan 27 responden tidak menuliskan

identitasnya.Sebagaimana terlihat pada tabel-tabel berikut ini :

Tabel 4.1.

Karakteristik Responden Berdasarkan Tingkat Pendidikan

\begin{tabular}{lcc}
\hline Tingkat pendidikan & Jumlah & Persentase $(\%)$ \\
\hline Pascasarjana & 6 & 15 \\
Sarjana & 24 & 60 \\
Diploma III & 2 & 5 \\
Setingkat SLTA & 8 & 20 \\
Total & 40 & 100 \\
\hline
\end{tabular}

Sumber : Data kuesioner diolah peneliti (2015)

Tabel 4.2.

Karakteristik Responden Berdasarkan Masa Kerja

\begin{tabular}{ccc}
\hline \multicolumn{1}{c}{ Masa Kerja } & Jumlah & Persentase $(\%)$ \\
\hline < dari 10 tahun & 6 & 15 \\
$>$ 10tahun -20 tahun & 7 & 17,5 \\
$>$ 20 tahun -35 tahun & 27 & 67,5 \\
\hline Total & 40 & 100
\end{tabular}

Sumber : Data kuesioner diolah peneliti (2015)

Tabel 4.3.

Karakteristik Responden Berdasarkan Jenis Kelamin

\begin{tabular}{lcc}
\hline \multicolumn{1}{c}{ Masa Kerja } & Jumlah & Persentase (\%) \\
\hline Laki-laki & 14 & 15 \\
Perempuan & 26 & 60 \\
21 tahun -35 tahun & 27 & 67,5 \\
\hline \multicolumn{1}{c}{ Total } & 40 & 100 \\
\hline
\end{tabular}

Sumber : Data kuesioner diolah peneliti (2015)

Dari tabel karakteristik Tingkat

Pendidikan sarjana, dengan masa 


\section{JENIUS}

kerja diatas 21 tahun dan jenis kelamin perempuan responden dalam penelitian ini yang paling tinggi.

\section{Uji Validitas Item.}

Hasil uji validitas menunjukan bahwaterdapat data yang tidak valid yaitu : pada variabel X1 pada item 12,13 , dan 17 , variabel $\mathrm{X} 2$ pada item $3,4,9,10,11,12,14,15$, dan 20. variabel X3 yaitu item 18. variabelY ada 10 item yaitu item 1, 3, 4, 5, 7, 8, 10, 14, 15, dan 18.Hal ini karena item tersebut memiliki r ritungkurang dari $r_{\text {tabel. }}$ Sedang item lainnya valid karena $\mathbf{r}_{\text {hitunglebih besar dari }}$ $\mathrm{r}_{\text {tabel.Item-item pertanyaan yang tidak }}$ valid akan dikeluarkan dan tidak diikutkan dalam uji selanjutnya yaitu uji reliabilitas.

\section{Uji Reliabilitas.}

Menurut Ghazali (2005:159). Dasar pengambilan keputusan untuk pengujian reliabilitas ditentukan nilai Cronbach Alpha berikut ini :

Jika $>0,60, \quad$ Kuesioner Reliabel

Jika $<0,60, \quad$ Kuesioner tidak Reliabel

Item-item yang masuk dalam uji reliabilitas adalah semua item yang valid.Berikut hasil uji reliabilitasnya

Tabel 4.4.

HasilUji Reliabilitas

\begin{tabular}{lccc}
\hline \multicolumn{1}{c}{ Variabel } & Alpha & Batas r hitung & Keputusan \\
\hline $\begin{array}{l}\text { Komunikasi } \\
\text { interpersonal (X1) }\end{array}$ & 0,600 & 0,600 & Reliabel \\
Disiplin kerja (X2) & 0,600 & 0,600 & Reliabel \\
Lingkungan Kerja (X3) & 0,600 & 0,600 & Reliabel \\
Kinerja pegawai (Y) & 0,600 & 0,600 & Reliabel \\
\hline
\end{tabular}

Sumber : Data Diolah Peneliti dari hasil printout program SPSSS (2015).

Nilai Cronbachalpha untuk ke empat variabel di atas 0,600. Karena nilai tersebut lebih besar dari 0,600 maka alat ukur kuisioner reliabel atau telah memenuhi syarat reliabilitas

Analisis Deskriptif Statistik. Analisis ini untuk mengetahui deskripsi data seperti mean, nilai minimum, nilai maksimum, dan standar deviasi. Berikut ini disajikan statistik deskriptif tentang variabelvariabel penelitian yaitu sebagai berikut

Tabel 4.5.

Hasil Analisis Deskriptif Statistik

\begin{tabular}{lccccc}
\hline & N & Minimum & Maximum & Mean & $\begin{array}{c}\text { Std. } \\
\text { Deviation }\end{array}$ \\
\hline Komunikasi & 67 & 27 & 59 & 46.28 & 5.903 \\
Interpersonal (X1) & & 12 & 37 & 27.78 & 4.827 \\
Disiplin Kerja (X2) & 67 & 22 & 65 & 49.58 & 6.840 \\
Lingkungan Kerja (X3) & 67 & 24 & 38 & 30.76 & 2.583 \\
Kinerja Pegawai (Y) & 67 & & & &
\end{tabular}


Valid N (listwise)

Sumber : Data Diolah Peneliti dari hasil printout program SPSSS (2015).

Deskripsi statistik tentang skor total dari variabel-variabel yang digunakan dalam penelitian ini. Skor total untuk variable kinerja pegawai jumlah data 67 , nilai minimum 24 , nilai maksimum 38 , rata-rata 30,76 , dan standar deviasi 2,583.

Penjumlahan skor dari variabel komunikasi interpersonal dengan jumlah data 67,memiliki nilai minimum 27, nilai maksimum 59, rata-rata 46,28, dan standar deviasi 5,903. Sedangkan variabledisiplin kerja dengan jumlah data 67 , nilai minimum 12 , nilai maksimum 37 , rata-rata 27,78 , dan standar deviasi
4,827. Variabel lingkungan kerja dengan jumlah data 67 , nilai minimum 22, nilai maksimum 65 , rata-rata 49,58, dan standar deviasi 6,840 .

\section{Uji Normalitas Data.}

Uji statistik One Sample Kolmogorov Smirnov.Kriteriapengujiannya sebagaimana disampaikan Santoso (2001:175)Jika nilai Signifikansi (Asym Sig 2 tailed), > 0,05, maka data berdistribusi normal.Jika nilai Signifikansi (Asym Sig 2 tailed < 0,05, maka data tidak berdistribusi normal.

Tabel 4.6.

Hasil Uji Normalitas Metode Kolmogorov Smirnov

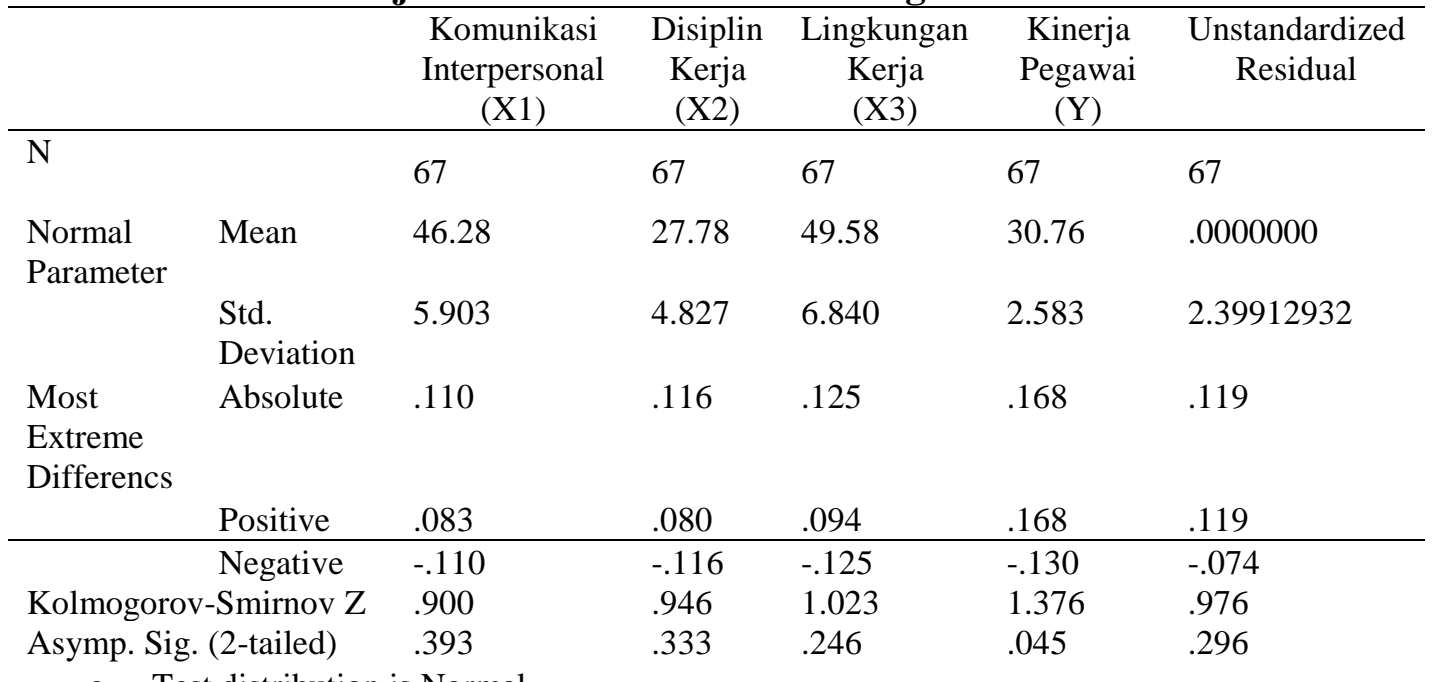

a. Test distribution is Normal

Sumber : Data Diolah Peneliti dari hasil printout program SPSSS (2015).

Nilai signifikansi (Asym.sig 2 tailed) untuk variabel Unstandardized Residual sebesar 0,296. Karena nilai lebih dari 0,05 , jadi residual terdistribusi normal.
Analisis Korelasi Pearson. Analisis hubungan antar variabel-variabel dapat dilihat pada tabel berikut :

Tabel 4.7.

Hubungan Komunikasi Interpersonal dengan Disiplin Kerja, 
Dan Lingkungan Kerja serta Kinerja Pegawai

\begin{tabular}{llllll}
\hline & & TotalX1 & TotalX2 & TotalX3 & TotalY \\
\hline TotalX1 & $\begin{array}{l}\text { Komunikasi } \\
\text { Interpersonal }\end{array}$ & 1 &, $800^{* *}$ &, $754^{* *}$ &, $262^{*}$ \\
TotalX2 & Disiplin Kerja &, $800^{* *}$ & 1 &, $843^{* *}$ &, 163 \\
TotalX3 & Lingkungan Kerja &, $754^{* *}$ &, $843^{* *}$ & 1 &, 036 \\
TotalY & Kinerja Pegawai &, $262^{*}$ &, 163 &, 036 & 1 \\
\hline
\end{tabular}

**. Correlation is significant at the 0.01 level (2-tailed).

*. Correlation is significant at the 0.05 level (2-tailed).

Sumber : Data Diolah Peneliti dari hasil printout program SPSSS (2015).

Hasil uji korelasi pearson adalah $0,262 *$, dan nilai $\mathrm{p}$ value $=0,032$ lebih kecil dari $\alpha=0,05$, maka Ho ditolak, hal ini menunjukan terdapat hubungan antara komunikasi interpersonal dengan kinerja pegawai yang cukup signifikan dengan tingkat hubungan "rendah".Hasiluji korelasi pearson pada variabel disiplin kerja terhadap kinerja pegawai sebesar 0,163 dan nilai $\mathrm{p}$ value $=0,186$ lebih besar dari $\alpha=$ 0,05, maka Ho di terima, hal ini menunjukan bahwa tidak terdapat hubungan disiplin kerja terhadap kinerja pegawai.

Selanjutnya hasil uji korelasi pearson variabel lingkungan kerja terhadap kinerja pegawai sebesar 0,036 dan nilai $\mathrm{p}$ value $=0,771$ lebih besar dari $\alpha=0,05$, maka Ho di terima, hal ini menunjukan bahwa tidak terdapat hubungan lingkungan kerja terhadap kinerja pegawai.Dari ketiga variabel bebas diatas terlihat hanya variabel komunikasi interpersonal yang memiliki hubungan yang positif dan signifikan, walau tingkat hubungan rendah. Namun data pada Tabel di atas terdapat hubungan antar variabel yang dapat penulis uraiankan sebagai berikut :

Selanjutnya hasil uji korelasi pearson $0,800^{* *}$, dan nilai $\mathrm{p}$ value $=0,000$ lebih kecil dari $\alpha=0,05$, maka Ho di tolak, hal ini menunjukan terdapat hubungan komunikasi interpersonal dengan disiplin kerja, yang cukup signifikan, dengan tingkat hubungan "sangat kuat", sedangkan hubungan variabel komunikasi interpersonal dengan lingkungan kerja, hasil uji korelasi pearson sebesar 0,754**, dan $p$ value $=0,000$ lebih kecil dari $\alpha$ $=0,05$, maka Ho di tolak, hal tersebut menunjukan terdapat hubungan yang signifikan dengan tingkat hubungan yang "Kuat".Hasiluji korelasi pearson variabel disiplin kerja terhadap lingkungan kerja sebesar $0,843^{* *}$ dan nilai $\mathrm{p}$ value $=0,000$ lebih kecil dari $\alpha=0,05$, maka Ho di tolak, menunjukan bahwa terdapat hubungan yang cukup signifikan dengan tingkat hubungan "Sangat Kuat".

\section{Analisis korelasi antar} dimensi Komunikasi 
Interpersonal

Kinerja Pegawai. terhadap

Analisis korelasi antar dimensi kinerja pegawai dalam penelitian ini dapat dilihat pada Tabel berikut ini:

Tabel 4.8.

Hubungan Komunikasi Interpersonal dan Kinerja Pegawai

\begin{tabular}{lcccccccccc}
\hline & Y02 & Y06 & Y09 & Y11 & Y12 & Y13 & Y16 & Y17 & Y19 & Y20 \\
\hline X101 &,- 129 &,- 008 &, $413^{* *}$ &, 184 &,- 050 &, 008 &, 196 &, 024 &, 196 &, $417^{* *}$ \\
X102 &,- 062 &, 119 &, 229 &, 105 &, 095 &,- 031 &, 109 &, 070 &, $351^{* *}$ &, $381^{* *}$ \\
X103 &,- 168 &, 217 &, 119 &, 192 &, 080 &,- 151 &, 191 &, 022 &, $287^{*}$ &, 225 \\
X104 &,- 138 &,- 005 &, $301^{*}$ &, 078 &,- 201 &,- 123 &, 065 &, 105 &, 053 &, $326^{* *}$ \\
X105 &,- 004 &,- 071 &, 238 &, 129 &,- 053 &, 070 &, 021 &, 155 &, 051 &, $272^{*}$ \\
X106 &, 075 &, 028 &, $279^{*}$ &, 113 &,- 069 &,- 100 &, 201 &, 109 &, 084 &, $307^{*}$ \\
X107 &,- 191 &,- 018 &, 186 &, 215 &, 171 &,- 041 &, 223 &, 012 &, $384^{* *}$ &, 230 \\
X108 &,- 108 &, 064 &, 166 &, 122 &,- 121 &,- 213 &, 096 &,- 068 &, 079 &, $327^{* *}$ \\
X109 &,- 130 &,- 133 &, 023 &, 088 &,- 042 &,- 023 &,- 022 &,- 050 &, 002 &, 234 \\
X110 &,- 119 &,- 054 &, $257^{*}$ &, $305^{*}$ &, 101 &, 074 &, 225 &, 068 &, $360^{* *}$ &, $304^{*}$ \\
X111 &, 039 &,- 019 &, $245^{*}$ &,- 076 &,$- 245^{*}$ &,- 030 &, 069 &,- 037 &, 052 &, $368^{* *}$ \\
X114 &,$- 332^{* *}$ &, 044 &, $259^{*}$ &, 119 &, 044 &, 029 &, 238 &,- 139 &, $325^{* *}$ &, 093 \\
X115 &,- 142 &, 040 &, $391^{* *}$ &, $392^{* *}$ &,- 012 &, 135 &, 059 &, 045 &, $292^{*}$ &,- 078 \\
X116 &,- 144 &, 056 &, 036 &, 128 &,- 127 &,- 032 &,- 047 &,- 050 &, $253^{* *}$ &, 139 \\
X118 &, 129 &,- 086 &, $256^{*}$ &, 124 &, 033 &, 180 &, 103 &, 141 &, 144 &,- 039 \\
X119 &,- 038 &,- 050 &, 044 &,- 035 &,- 071 &, 006 &, 004 &,- 047 &,- 016 &, 021 \\
X120 &, 004 &, 186 &, $330^{* *}$ &, 223 &, 134 &, 120 &, $255^{*}$ &, $360^{* *}$ &, $286^{*}$ &, 069 \\
\hline
\end{tabular}

Sumber : Data Diolah Peneliti dari hasil printout program SPSSS (2015).

2. Analisis korelasi antar dimensi Disiplin Kerja dengan Kinerja Pegawai.

Selanjutnya beberapa hasil analisis korelasi dimensi antara disiplin kerja terhadap kinerja pegawai pada Kantor Pusat LPP TVRI, dapat dilihat pada Tabel dibawah ini :

Tabel 4.9.

Analisis korelasi antar dimensi

Disiplin Kerja dengan Kinerja Pegawai.

\begin{tabular}{ccccccccccc}
\hline & Y02 & Y06 & Y09 & Y11 & Y12 & Y13 & Y16 & Y17 & Y19 & Y20 \\
\hline X201 &,- 106 &, 063 &, 047 &, 090 &,- 033 &,- 048 &, 124 &, 036 &,- 014 &, 082 \\
X202 &,- 119 &, 158 &, 012 &, 108 &,- 021 &,- 097 &, 110 &,- 001 &,- 022 &, $296^{*}$ \\
X205 & &,- 046 &, $345^{* *}$ &, 113 &,- 145 &, 031 &, 218 &,- 018 &,- 104 &, $275^{*}$ \\
X206 &, 013 &,- 057 &, $294^{*}$ &, 068 &,- 072 &,- 033 &, 127 &, 030 &, 074 &, $307^{*}$ \\
X207 &,- 010 &,- 013 &, 215 &, 105 &,$- 262^{*}$ &,- 065 &,- 019 &,- 062 &, 042 &, $353^{* *}$ \\
X208 &,- 074 &,- 077 &, 201 &, 082 &,- 007 &,- 078 &, $297^{*}$ &, 110 &, 168 &, $340^{* *}$ \\
X213 &, 027 &,- 119 &, 105 &, $269^{*}$ &, 059 &,- 157 &, 065 &, 092 &, $253^{*}$ &, 029 \\
X216 &,- 163 &,- 042 &, 171 &, 166 &, 009 &,- 157 &, 206 &,- 072 &, 139 &, $416^{* *}$ \\
X217 &, 055 &,- 015 &, $255^{*}$ &, 180 &,- 020 &,- 126 &, 153 &,- 073 &, 158 &, $375^{* *}$ \\
X218 &,- 067 &,- 106 &, 189 &, $329^{* *}$ &, 038 &,- 039 &, 134 &,- 144 &, 183 &, 055
\end{tabular}



, 176 $-, 113$ $-, 084$ , 058 $-, 107$ , 102 , 026

Sumber : Data Diolah Peneliti dari hasil printout program SPSSS (2015).

3. Analisis korelasi antar Hasil analisis korelasi antar dimensi dimensi Lingkungan Kerja lingkungan kerja terhadap kinerja dengan KinerjaPegawai. pegawai Kantor Pusat LPP dapat dilihat pada Tabel berikut ini :

Tabel 4.10.

Uji Korelasi lingkungan kerja terhadap kinerja pegawai

\begin{tabular}{|c|c|c|c|c|c|c|c|c|c|c|c|}
\hline & & Y02 & Y06 & Y09 & Y11 & Y12 & Y13 & Y16 & Y17 & Y19 & Y20 \\
\hline $\mathrm{X} 30$ & Pearson & & & & & & & & & & \\
\hline 1 & $\begin{array}{c}\text { Correlatio } \\
\mathrm{n}\end{array}$ &,- 009 & ,041 & ,099 &, 110 &,$- 277^{*}$ &, $349^{* *}$ &,- 074 &,- 113 & ,303* & ,256* \\
\hline $\mathrm{X} 30$ & Pearson & & & & & & & & & & \\
\hline 2 & $\begin{array}{c}\text { Correlatio } \\
n\end{array}$ &,- 044 & ,012 & ,013 & ,033 &, $317^{* *}$ &, $333^{* *}$ &,- 114 &,- 177 & ,201 &, 141 \\
\hline X30 & Pearson & & & & & & & & & & \\
\hline 3 & $\begin{array}{c}\text { Correlatio } \\
n\end{array}$ &,- 084 &,- 025 &, 044 & ,005 &,- 218 &,$- 265^{*}$ &,- 107 &,- 135 & ,097 & , 325 \\
\hline $\mathrm{X} 30$ & Pearson & & & & & & & & & & \\
\hline 4 & $\begin{array}{c}\text { Correlatio } \\
n\end{array}$ &,- 135 &,- 067 &, 024 & ,034 &,- 196 &,- 126 &,- 068 &,- 110 & ,002 & ,289* \\
\hline $\mathrm{X} 30$ & Pearson & & & & & & & & & & \\
\hline 5 & $\begin{array}{c}\text { Correlatio } \\
\mathrm{n}\end{array}$ &,$- 269^{*}$ &,- 081 & ,193 & ,067 &,- 206 &,- 215 &, 062 &,- 231 &,- 005 &, $278^{*}$ \\
\hline $\mathrm{X} 30$ & Pearson & & & & & & & & & & \\
\hline 6 & $\begin{array}{c}\text { Correlatio } \\
n\end{array}$ &,- 189 &,- 122 & ,070 &, 041 &,- 223 &,- 168 &, 023 &,- 149 &,- 049 & ,099 \\
\hline X30 & Pearson & & & & & & & & & & \\
\hline 7 & $\begin{array}{c}\text { Correlatio } \\
n\end{array}$ &,- 004 & ,138 &, 088 &, 140 &, 044 &,- 027 &, 114 &,- 064 & ,281* &, $250^{*}$ \\
\hline $\begin{array}{c}X 30 \\
8\end{array}$ & $\begin{array}{c}\text { Pearson } \\
\text { Correlatio } \\
\mathrm{n}\end{array}$ &,- 101 &,- 071 & ,192 & ,208 &,- 068 &,- 021 &, 160 &,- 005 & ,298* & ,349* \\
\hline X30 & Pearson & & & & & & & & & & \\
\hline 9 & $\begin{array}{c}\text { Correlatio } \\
\mathrm{n}\end{array}$ &,- 067 &, 047 & ,189 & ,207 &,- 124 &,- 093 & ,086 &,- 083 & ,063 & ,293* \\
\hline $\mathrm{X} 31$ & Pearson & & & & & & & & & & \\
\hline 0 & $\begin{array}{c}\text { Correlatio } \\
n\end{array}$ &,- 099 &,- 090 &, 225 & ,208 & ,026 &,- 014 & ,125 &,- 052 & ,079 & ,131 \\
\hline $\begin{array}{c}\mathrm{X} 31 \\
1\end{array}$ & $\begin{array}{c}\text { Pearson } \\
\text { Correlatio } \\
n\end{array}$ & ,092 &,- 040 & , 021 & , 169 &,- 074 &,- 144 &,- 094 & ,006 &,- 151 &,- 117 \\
\hline $\begin{array}{c}\mathrm{X} 31 \\
2\end{array}$ & $\begin{array}{c}\text { Pearson } \\
\text { Correlatio } \\
n\end{array}$ &,- 085 &,- 049 & , 243 & ,105 &,- 040 &,$- 245^{*}$ &, $268^{*}$ &, 022 & $\begin{array}{l}377^{*} \\
*\end{array}$ & ,043 \\
\hline $\begin{array}{c}X 31 \\
3\end{array}$ & $\begin{array}{c}\text { Pearson } \\
\text { Correlatio } \\
n\end{array}$ &,- 173 & ,033 & , 258 &, $317^{*}$ & ,018 &,- 138 &, 122 &,- 045 &, $332^{*}$ &, $258^{*}$ \\
\hline $\begin{array}{c}X 31 \\
4\end{array}$ & $\begin{array}{c}\text { Pearson } \\
\text { Correlatio } \\
\mathrm{n}\end{array}$ & $\begin{array}{c}- \\
, 353^{* *}\end{array}$ &,- 100 &, 155 & ,281* &, 022 &,- 198 & ,197 &,- 113 &, $247^{*}$ &,- 010 \\
\hline $\begin{array}{c}\mathrm{X} 31 \\
5\end{array}$ & $\begin{array}{c}\text { Pearson } \\
\text { Correlatio } \\
n\end{array}$ & 0,000 & 0,000 &, 110 &, 225 & ,099 &,- 099 & $\begin{array}{c}0,00 \\
0\end{array}$ &, 113 &, 110 &,- 175 \\
\hline $\begin{array}{c}X 31 \\
6\end{array}$ & $\begin{array}{c}\text { Pearson } \\
\text { Correlatio } \\
\mathrm{n}\end{array}$ & ,023 &,- 014 & , 038 & ,148 & ,006 &,- 194 &,- 095 &,- 142 & ,077 &,- 084 \\
\hline
\end{tabular}




\begin{tabular}{|c|c|c|c|c|c|c|c|c|c|c|c|}
\hline X31 & Pearson & & & & & & & & & & \\
\hline 7 & $\begin{array}{c}\text { Correlatio } \\
n\end{array}$ &,- 042 & ,023 & ,105 & ,095 &,- 102 &,$- 281^{*}$ &,- 058 &, $274^{*}$ & , $251^{*}$ & , 122 \\
\hline X31 & Pearson & & & & & & & & & & \\
\hline 9 & $\begin{array}{c}\text { Correlatio } \\
n\end{array}$ & , 058 &, $345^{* * *}$ & 147 & , 021 &,- 077 &,- 023 &,- 044 & , 066 &,- 150 & 227 \\
\hline X32 & Pearson & & & & & & & & & & \\
\hline 0 & $\begin{array}{c}\text { Correlatio } \\
n\end{array}$ &,- 082 &,- 144 & , 150 & ,230 & ,055 &, $264^{*}$ &,- 019 &,- 089 &,- 154 & ,216 \\
\hline
\end{tabular}

Sumber : Data Diolah Peneliti dari hasil printout program SPSSS (2015)

\section{PENUTUP}

\section{Kesimpulan}

1. VariabelKomunikasi

Interpersonal memiliki hubungan yang positif, dan signifikan dengan tingkat hubungan yang “ rendah" terhadap variabel Kinerja Pegawai Kantor Pusat LPP TVRI.

2. Variabel Disiplin Kerja tidak memiliki hubungan terhadap variabel Kinerja Pegawai Kantor Pusat LPP TVRI.

3. Variabel Lingkungan Kerja tidak memiliki hubungan terhadap Kinerja Pegawai Pusat LPP TVRI.

4. Terdapat Hubungan antara Dimensi Komunikasi Interpersonal dengan Disiplin Kerja, yang signifikan, dengan tingkat hubungan "sangat kuat".

5. Terdapat Hubungan antar Dimensi Komunikasi Interpersonal dengan Lingkungan Kerja, yang positif dan signifikan, dengan tingkat hubungan "kuat".

6. Terdapat Hubungan yang positif dan signifikan, dengan tingkat hubungan "sangat kuat", antara Dimensi Disiplin Kerja Terhadap Lingkungan Kerja.

\section{Saran.}

Setelah melihat hasil analisis dalam penelitian ini,terutama terkait dengan hubungan antar dimensi komunikasi interpersonal, disiplin kerja dan lingkungan kerja terhadap kinerja pegawai, menunjukan terdapat faktor-faktor lain yang dapat mempengaruhi kinerja pegawaipada Kantor Pusat LPP TVRI diantaranya adalah perlu membangun semangat atau motivasi pegawai, dan mengupayakan sikap teladan yang diberikan pimpinan serta kompensasi atau penghargaan bagi pegawai dapat membuat pegawai cepat menyelesaikan pekerjaannya, yang pada akhirnya dapat meningkatkan kinerja pegawai, sehingga untuk penelitian selanjutnya perlu dilakukan penelitian mengenai motivasi, teladan pimpinan dan kompensasi dalam peningkatan kinerja pegawai.

\section{DAFTAR PUSTAKA}

Alhusin, Syahri, (2003)“Aplikasi Statistik Praktis dengan Menggunakan SPSS 10 forWindows", Edisi Kedua, Yogyakarta: Graha Ilmu.

Asamu Festus Femi. (2014). The Impact of Communiaction on Workers'Performance selected Organisations in Lagos State, Nigeria. IOSR Journal Of Humanities And Social Science (IOSR-JHSS) Volume 19, Issue 8, 
Ver. II (Aug. 2014), PP 75-82 eISSN: 2279-0837, p-ISSN: 22790845 .

Altin Uka. (2014). The Communication and Its Influence on the Effectiveness of the Organization.Mediterranean Journal of Social Sciences. MCSER Publishing, Rome-Italy Vol. 5 No 2. E-ISSN 2039-2117. ISSN 2039-9340.

Alsayed, Alaedin Khalil, Mohammad Hossein Motaghi, Intan Binti Osman.(2012).The Relationship between Communication Satisfaction and Performance Indicators in Palestinian Governmental Organization.International Journal of Scientific and Research Publications, Volume 2, Issue 11, pp 1-9.

Beny Usman, (2013). Pengaruh Komunikasi Interpersonal Terhadap Kinerja Pegawai Pada Fakultas Ekonomi Universitas PGRI Palembang.

Chirasha, Vonai.(2013). Management of Discipline for good Performance: A theoretical perspective.Online Journal of Social Sciences Research. ISSN 2277-0844, Volume 2, Issue 7, pp 214-219.

Chandrasekar.(2011). Workplace Environment and Its Impact on Organizational Performance Organisations in Public Sector Organisations.

International Journal of Enterprise Computing and Business Systems. Vol. 1.

Emad Y. Masoud, Tahreer Abu Hmeidan. (2013). The Effect Of Perceiived Work Environment On Frontline Employees' Service
Recovery Performance The Case Of Four And Five Star Hotels In Jordan.European Scientific Journal.edition vol.9, No.11 ISSN: $1857-7881$.

Endang Setyaningdyah , Umar Nimran, Kertahadi, Armanu Thoyib.(2013). The Effects of Human Resource Competence, Organisational Commitment and Transactional Leadership on Work Discipline, Job Satisfaction and Employee's Performance.Interdisciplinary Journal of Contemporary Research. Volume 5, No 4.

Emmanuel Majekodunmi Ajala. (2012). The Influence Of Workplace Environment On Workers' Welfare, Performance And Productivity.The African Symposium: An online journal of the African Educational Research Network

Farid Nanda, Nasir Azis, Iskandarsyah Madjid (2014). Pengaruh Rotasi Kerja, Komunikasi Interpersonal dan Gaya Kepemimpinan Terhadap Motivasi Kerja Serta Dampaknya Pada Prestasi Kerja Pegawai Bapedal Aceh.

Foury Erawati.(2014). Pengaruh Supervisi, Lingkungan Kerja dan Insentive Terhadap Kinerja Pegawai Pada KPP Madya DKI Jakarta.Jurnal Bisnis dan Manajemen EksekutifVol.1 No. 1, 2014, artikel 5.

Ghazali, Imam, 2011, Aplikasi Analisis Multivariat.Dengan Program IBM SPSS 19, Cetakan kelima, Universitas Diponegoro, Yogyakarta.

Hardjana Agus. M, 2003, Komunikasi Interpersonal dan 
Interpersonal,

Kanisius,Yogyakarta.

Hidayat, Iman. (2007).Hubungan Antara Gaya Kepemimpinan dan Komunikasi Interpersonal dengan Kepuasan Kerja Pegawai Pada Badan Kepegawaian Daerah Kota Palembang.

Hassan Zarei Matin, Golamreza Jandaghi, Fateme Haj Karimi, Ali Hamidizadeh. (2010). Relationship between Interpersonal Communication Skills and Organizational Commitment (Case Study: Jahad Keshavarzi and University of Qom, Iran). European Journal of Social Sciences. Volume 13, Number 3 (2010).

Iskandar, Iwan. (2006).Analisis Pengaruh Motivasi dan Disiplin Kerja Terhadap Produktivitas Pegawai Negeri Sipil di Lingkungan Kantor Pelayanan Pajak Palembang Seberang Ulu.Program Pascasarnaja Magister Manajemen Universitas Tridinanti Palembang.

Imran., Afsheen Fatima., Arshad Zaheer., Imran Yousaf and Batool. (2012). How to Boost Employee Performance: Investigating the Influence of Transformational Leadership and Work Environment in a Pakistani Perspective.Middle-East Journal of Scientific Research.11 (10): 1455-1462, 2012. ISSN 19909233.

Jain, Ruchi, Surinder Kaur. (2014).Impact of Work Environment on Job Satisf action.International Journal of Scientific and Research Publications, Volume 4, Issue 1, pp.1-8.
Khan, Abdul Ghafoor, Furqan Ahmed Khan, Muhammad Aslam Khan.(2011). Impact of Training and Development on Organizational

Performance.Global Journal of Management and Business Research.Vol. 11 Issue 7 Version 1.0.

Mark Alexander. (2012). Employee Performance and Discipline Problems;A New Approach. Industrial Relations Centre.

Monday Osemeke. (2008). Effective Communication And Performance Improvement In Nigeria.Journal Of Research In National Development, volume 6.

Muhammad, Arni.(2000). "Manajemen Komunikaasi, Bumi Aksara". Jakarta.

Nunnaly, J.C., "Psychometric Theory", $2^{\text {nd }}$ edition, New Delhi: Tata McGraw Hill, 1981.

Nitisemito, Alex S.(1986). Manajemen Personalia : Manajemen Sumber Daya Manusia, Ghalia Indonesia, Jakarta.

Nuria Erisna. (2012). Hubungan Disiplin dan Motivasi Kerja dengan Kinerja Pegawai pada Dinas Pendidikan Kabupaten Way Kanan.

Nazari, Rasool, Mohammad Ehsani, Faredeh Ashraf Gangoei and Hamid Ghasemi.(2013). "The Effects of Communication Skills and Interpersonal Communication onOrganizational Effectiveness of Iranian Sport Managers and Presenting a Model"..Middle-East Journal of Scientific Research Vol.10, No.6, pp 702-710.

Nina Munira Naharuddin., Mohammmad Sadegi. (2013). 
Factors Workplace Environment that Affect Employees Performance : A Case Study of Miyazu Malaysia.International Journal of Independent Research and Studies - IJIRS. Vol.2, No.2, 66-78.

Nurhidayati.(2014). Analisis Pengaruh Motivasi dan Disiplin Kerja Terhadap Kinerja Karyawan PT. Kemilau Indah Permana Kebak Kramat Karanganyar.

Rabia Imran, Afsheen Fatima, Arshad Zaheer, Imran Yousaf and Iram Batool.(2012). How to Boost Employee Performance Investigating the Influence of Transformational Leadership and Work Environment in a Pakistani Perspective.Middle-East Journal of Scientific Research.Vol 10 No 11, pp 1455-1462.

Rahayu Puji Suci, Mohamad Syafi'I Idrus. (2015).The Influence of Employee Training and Discipline Work against Employee Performance PT. Merpati Nusantara Airlines (Persero).Review of European Studies; Vol. 7, No. 11, pp 7-14.

Sedarmayanti.(2007). Manajemen Sumber Daya Manusia : Reformasi Birokrasi dan Manajemen Pegawai Negeri Sipil, PT. Refika Aditama, Bandung.

Sukmalana, Soelaiman, (2007).Manajemen

Kinerja:Langkah Efektif untuk Membangun, Mengendalikan, dan Evaluasi Kinerja, PT. Intermedia Personalia Utama, Jakarta.

Suharsimi, Arikunto. (2002). "Prosedur Penelitian : Suatu Pendekatan Praktek",Edisi Revisi V, Jakarta: PT Rineka Cipta.
Sugiyono.(2010). Metode Penelitian Bisnis, Bandung: CV. Alfabeta.

Sudarto, Suwardi Lubis, Paldi Hidayat. (2009).Pengaruh Komunikasi Interpersonal, dan Motivasi Terhadap Kinerja Karyawan pada PT. Westfalia Indonesia.

Tiur Asi Siburian. (2013). Pengaruh Komunikasi Interpersonal, Budaya Kerja, Kepuasan Kerja, Motivasi terhadap Komitmen Para Guru Sekolah Negeri di Kabupaten Humbang Hasundutan, Sumatera Utara.

Wibowo. (2007). Manajemen Kinerja, PT. Raja Grafindo Persada, Jakarta.

Veithzal, Rivai, 2004, Manajemen Sumber Daya Manusia untuk Perusahaan. Dari teori ke paraktek, PT. Raja Grafindo Persada, Jakarta.

(2004),

Kepemimpinan dan Prilaku Organisasi, PT. Raja Grafindo Persada, Jakarta 